\title{
Effect of acceptance and commitment therapy on body image flexibility and body awareness in patients with psychosomatic disorders: a randomized clinical trial
}

\author{
Reza Givehki ${ }^{1}$, Hamid Afshar ${ }^{2}$, Farzad Goli ${ }^{3,4}$, Carl Eduard Scheidt ${ }^{5}$, Abdollah Omidi ${ }^{6,7}$, Mohammadreza \\ Davoudi $^{8}$
}

${ }^{1}$ MD., Psychosomatic Research Center, Isfahan University of Medical Sciences, Isfahan, Iran

${ }^{2}$ MD., Psychosomatic Research Center and Department of Psychiatry, School of Medicine, Isfahan University of Medical Sciences, Isfahan, Iran

${ }^{3}$ MD., Head of Danesh-e Tandorosti Institute, Isfahan, Iran

${ }^{4}$ Professor, Faculty Instructor, Energy Medicine University, California, USA

${ }^{5}$ MD., Department of Psychosomatic, Albert Ludwigs University, Freiburg, Germany

${ }^{6}$ Ph.D. of Clinical Psychology, Associate Professor, Department of Clinical Psychology, Faculty of Medicine, Kashan University of Medical Sciences, Kashan Iran

${ }^{7}$ Psychosomatic Research Center, Isfahan University of Medical Sciences, Isfahan, Iran

${ }^{8}$ M.Sc. Student of Clinical Psychology, Department of Clinical Psychology, School of Medicine, Kashan University of Medical Sciences, Kashan, Iran

Type of article: Original

\begin{abstract}
Objective: The aim of this research was to examine the effectiveness of the acceptance and commitment therapy (ACT) for body image flexibility and body awareness in these patients.

Methods: A randomized clinical trial was conducted at Kashan University of Medical Sciences clinics in Kashan, Iran, from December 1, 2017 to March 30, 2018. A sample of 75 patients with psychosomatic disorders was selected by convenience sampling. The selected patients were randomly divided into three 25 -member groups. The experimental group received medicinal treatment combined with the (ACT). The active control group received the usual treatment plus psycho education in general psychology, and the treatment group solely received the medicinal treatment usually used in the treatment centers. The results were obtained using the following scales in the pretest and posttest phases and the two-month follow-up: the demographic questionnaire; Shields' body awareness questionnaire; and Sandoz's body image flexibility questionnaire. The data were analyzed using the descriptive statistics tests (mean and standard deviation) and the repeated measures analysis of variance and chi-square tests in IBM-SPSS version 21.

Results: There was no significant difference among the three groups in terms of body image flexibility, body awareness, somatic symptoms, and demographic variables. The results of the posttest and follow-up examinations suggested that the ACT group more effectively and significantly improved body image flexibility and body awareness as compared to both of the control groups ( $\mathrm{p}=0.02$ ).

Conclusions: The ACT successfully improves body image flexibility and body awareness in patients with psychosomatic disorders.

Clinical trial registration: This research was registered at the Iranian Registry of Clinical Trials (http://www.irct.ir) with the IRCT ID: IRCT2017092532057N2.

Funding: Research and Technology Department of Kashan University of Medical Sciences funded the study (Ref: 96053).

Keywords: Acceptance and commitment therapy, Body image flexibility, Body awareness, psychosomatic disorders
\end{abstract}

\section{Corresponding author:}

Associate professor Dr. Abdollah Omidi.

Tel: + 98-31-55540021, Fax: +98-31-55540021, E-mail: abomidi20@yahoo.com

Received: February 28, 2018, Accepted: May 23, 2018, Published: July 2018

iThenticate screening: May 23, 2018, English editing: June 02, 2018, Quality control: June 16, 2018

This article has been reviewed / commented by four experts

Ethics approval: IR.KAUMS.MEDNT.REC.1396.6 (Kashan University of Medical Sciences)

(C) 2018 The Authors. This is an open access article under the terms of the Creative Commons Attribution-NonCommercialNoDerivs License, which permits use and distribution in any medium, provided the original work is properly cited, the use is non-commercial and no modifications or adaptations are made. 


\section{Introduction}

Somatic symptom disorder and other disorders with prominent somatic symptoms constitute a new category in DSM-5 called somatic symptom and related disorders (1). Of all the common disabling psychiatric disorders, psychosomatic disorders have been specially considered in recent years $(1,2)$. These disorders include the somatic symptoms disorder, the illness anxiety disorder, the factitious disorder, the conversion disorder, and psychological conditions influencing physical diseases (1). Based on the latest research findings, the average prevalence of these disorders in the clinical population visiting the medical centers varies from 6 to $15 \%(3,4)$. Multiple studies suggest that somatic symptom disorder is common and occurs most often in primary-care patients (5-8). Numerous studies have been conducted in this field, which have provided a significant insight into the pathophysiology, epidemiology, socioeconomic factors, and the role of the specific medical-psychological interventions (9-11). Given the psychological, social, and health consequences of body image dissatisfaction and associated disordered eating attitudes and behaviors, we hope that formats across a wide age range of populations can be applied flexibly to various types of body image problems $(12,13)$. Individuals with chronic health conditions are susceptible to high levels of body image distortion $(14,15)$. Health problems that result in changes in physical features can impact selfperception and increase body image dissatisfaction and disordered healthy behavior (16). The study by Schmidt and Treasure (17), provides a literature review that documents how disordered behaviors (such as eating and impulsivity) are avoidance-based coping strategies that allow one to suppress "negative" emotions. However, immediate consequences are more effective than delayed consequences at controlling behavior (18). Recent theoretical approaches to psychological suffering have pointed out the role of psychological inflexibility especially body image flexibility in several psycho somatic symptoms (19). Psychological inflexibility encompasses an inability to be in the present moment, as well as actions motivated by avoidance of difficult internal experiences (20). Similar to the other psychiatric disorders, medical therapies have been widely administered for these disorders, but the results suggest that these patients often resist psychiatric treatments $(21,22)$. In addition, these treatments are incapable of solving psychological problems especially body-related awareness problems in these patients $(23,24)$.

As a consequence, psychotherapeutic methods have been widely used to this end. As the treatment commonly administered for psychosomatic problems, the cognitive behavioral therapy (CBT) has displayed considerable advantages in treating these disorders (25). Despite the useful results of CBT, this treatment faces serious limitations in patients with psychosomatic disorders. Firstly, in the cognitive behavioral therapy, it is necessary to repeatedly challenge the patients on their unreasonable thoughts and beliefs, and according to the results, many psychiatric patients fail to tackle these challenges. In many cases, patients are even unable to critically challenge their distorted thoughts and perceptions due to the nature of their diseases $(26,27)$. On the other hand, in addition to the psychosomatic symptoms, which form the core of these disorders, patients face significant body awareness and body image flexibility issues. There is ample evidence suggesting that the cognitive behavioral therapy lacks the capacity for solving the underlying problems associated with body awareness and its acceptance, and these problems are sometimes co morbid with the other disorders $(28,29)$. Furthermore, awareness (including body awareness) in traditional cognitive behavioral therapy has been less widely considered $(29,30)$. Body awareness involves awareness of one's inner feelings and concentration on the awareness of the inner feelings and moods. Body awareness also refers to the perceptual capacity and the distinction between the information obtained from all of the sensory organs such as the proprioceptors in the muscles and joints, which are focused on the association between the person's body and his/her perception of their body $(23,24,31)$.

Due to its experiential nature, acceptance and commitment therapy (ACT) suits a wide range of individuals for not challenging the patient's thoughts (32). Secondly, ACT is a mindfulness-based therapy, and increased body awareness and acceptance are substantially important to mindfulness and can significantly contribute to the settlement of psychosomatic problems $(32,33)$. ACT consists of six core processes that result in psychological flexibility $(32,34)$. In this model, experiential avoidance is a construct with an important role in psychopathology and is used to avoid the painful experience. Some benefits of this treatment are that it is brief; it has successfully been applied in groups and individually $(5,33)$. Notwithstanding the above background, very few studies have been conducted to investigate the effectiveness of this therapy for patients with psychosomatic problems, and the existing research has been restricted by methodological limitations such as small sample size and many confounding factors $(30,35,36)$; hence, the present research was carried out to study the effect of the acceptance and commitment therapy on body image and body awareness in patients with psychosomatic problems.. 


\section{Material and Methods}

\subsection{Trial design and participants}

This study was a single-blind randomized clinical trial consisting of the pretest, posttest and follow-up phases and two control groups. The study population included all patients diagnosed with a psychosomatic disorder according to the Diagnostic and Statistical Manual of Mental Disorders-4th Edition (DSM-5), from December 1, 2017 to March 30, 2018 by a psychiatrist, an internist, or a Ph.D. clinical psychologist in the given university clinics.

\subsection{Selection criteria}

The inclusion criteria were as follows: 1) patients aged 19 to 50 years; 2) patients diagnosed with a psychosomatic disorder based on DSM-5; 3) no history of hospitalization for a schizophrenia spectrum or other psychosis disorder; 4) lack of any co-morbid psychiatric disorder; and 5) no history of drug abuse. The exclusion criteria were the abuse of drugs during the interventions and the follow-up, absence more than two sessions, and unwillingness to continue the treatment.

\subsection{Sample size}

Based on the previous research (37) the sample size calculated for each group was approximately 20 at the confidence interval of $95 \%$ and with a type II error of $20 \%$. However, considering the possible attrition and the other possible confounding factors, this figure was increased by $20 \%$ to have 25 patients in each group (total $=75$ ).

\subsection{Randomization and blinding}

For data collection of this single-blind randomized trial, all somatic symptom disorders patients who were diagnosed through clinical interview based on DSM- 5, and referred to four clinics in Kashan University of Medical Sciences during the study period, were considered. According to inclusion criteria, 75 patients were selected and a number was assigned to each participant. The participants were divided into three groups using the permuted blocked randomization (25 participants per group): 1) the first group received the ACT and treatment as usual (TAU), 2) the active control group received general psycho-education plus the TAU, 3) the TAU group only received the usual medicinal treatment. Figure 1 shows the study flow diagram based on CONSORT 2010.

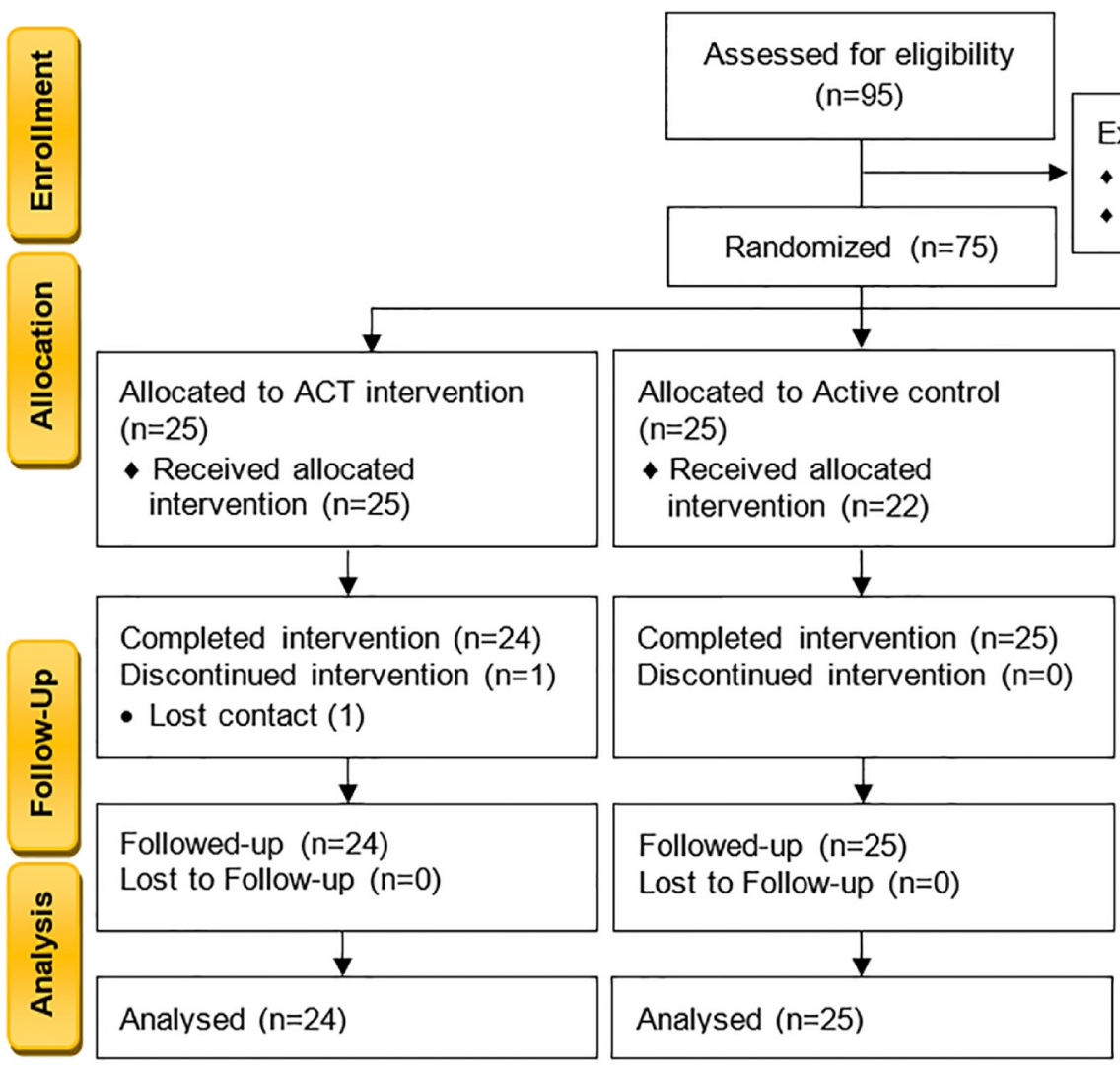

Excluded $(n=20)$

- Not meeting inclusion criteria $(n=16)$

- Other reasons $(n=4)$

Figure 1. CONSORT 2010 Flow Diagram

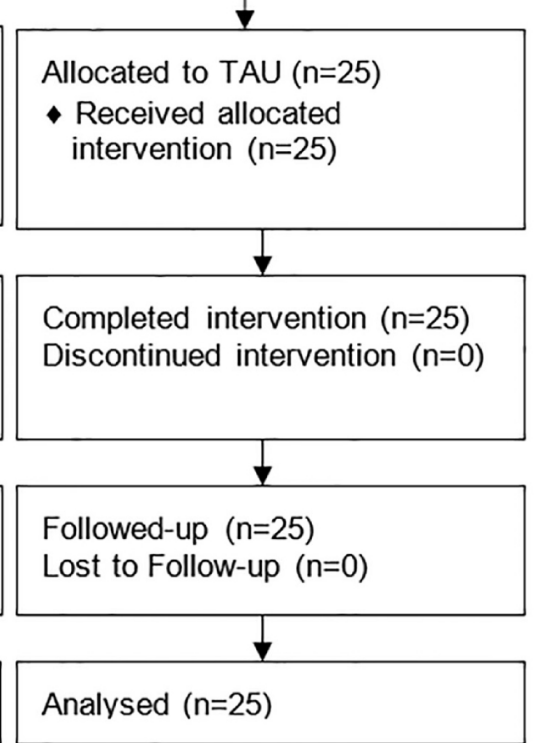




\subsection{Outcomes}

The first outcome was studying the level and amount of body image flexibility and body awareness in the three ACT, active control and TAU groups after the intervention, and the second outcome was studying the level and amount of body image flexibility and body awareness in the three groups after two months.

\subsection{Instruments}

The Demographic Information Questionnaire: This researcher-made questionnaire was developed by the first author to examine age, gender, marital status, the diagnosed psychosomatic disorder, academic status, and occupational status.

2.6.1. Body-Image Acceptance and Action Questionnaire (BI-AAQ):

It was developed by Sandoz et al. to measure body image flexibility. This 12 -item scale is rated based on the 7-point Likert scale with minimum and maximum scores of 12 and 84, respectively. Higher scores show lower body image flexibility. The test-retest reliability of this questionnaire was reported to be 0.81 by Bond et al., and its reported internal consistency was 0.84 . The results of the confirmatory factor analysis revealed that the single-factor pattern of the body image flexibility questionnaire displayed good fitness in the Iranian society. To assess the reliability of this questionnaire, the internal consistency of this scale was assessed using Cronbach's alpha coefficient and the result was 0.87 . In addition, the calculated test-retest coefficient for this scale was $0.72(38,39)$.

2.6.2. Body awareness questionnaire $(B A Q)$ :

This psychological dimension was assessed using Shields' body awareness questionnaire, which an 18-item questionnaire is designed to assess the attention paid to the normal physical processes not associated with emotions. The items are rated based on the 9-point Likert scale and the options vary from "Totally false" to "Totally true". Shields et al. assessed the internal consistency of this scale using Cronbach's alpha coefficient, which was 0.82 for this scale. The retest reliability of this questionnaire was acceptable at a two-week interval ( $\mathrm{r}=0.80)$. The Cronbach's alpha coefficient of the body awareness questionnaire was also acceptable in the Iranian sample $(\mathrm{a}=0.88)(40)$. 2.6.3. Psychosomatic disorders:

In this research, diagnosis was done by a psychiatrist, clinical psychologist or internist on patients who have one of the psychosomatic disorders, by using DSM-5 (1).

\subsection{Therapeutic interventions}

The treatment plan was designed using the model proposed based on the theoretical model of acceptance and commitment therapy for body image dissatisfaction and improvement in mindfulness skills, which had been developed by Pearson et al. (10). This model involved 10 weekly 90 -minute sessions (41) (Table 1).

Table 1. A summary of the contents of the ACT sessions (41)

\begin{tabular}{|c|c|}
\hline Description & Session \\
\hline Developing a rapport, explaining the intervention, performing the "raisin eating" exercise, and breathing exercise & 1 \\
\hline $\begin{array}{l}\text { Teaching and exercising mindfulness, reviewing the previous session homework, identifying the thoughts and } \\
\text { emotions and the relationship between them, teaching the memorization of pleasant life events, focusing on the } \\
\text { breathing exercise and extending mindfulness, creating creativity from hopelessness, building the table of the } \\
\text { consequences of the schema coping behaviors (SCBs), and teaching the defusion techniques }\end{array}$ & $2-5$ \\
\hline $\begin{array}{l}\text { Teaching defusion with an emphasis on valuation versus description; examining willingness versus inevitable } \\
\text { pain and absence from relationships; examining self-evaluation versus discussion; reinforcement of self as } \\
\text { context versus self as content using the chess metaphor and visualization of the worst condition; assessing the } \\
\text { costs of avoiding painful emotions through experiential exercises, the tug of war exercise, and the self as } \\
\text { observer exercise; and homework assignment }\end{array}$ & $6-8$ \\
\hline $\begin{array}{l}\text { Reviewing the previous session's homework; mental visualization; exercising defusion and alternative responses; } \\
\text { visualizing mindfulness and developing compassion for pain resulting from the body image; and homework } \\
\text { assignment }\end{array}$ & 9 \\
\hline $\begin{array}{l}\text { Creating mindfulness; improving self-compassion and compassion for others; reviewing the homework; holding } \\
\text { group discussions over the previous session exercises; role-playing and offering alternative responses to events } \\
\text { caused by body image; discussing the barriers, developing strategies for valuable actions, and invoking } \\
\text { commitment to valuable actions; performing post-treatment evaluations }\end{array}$ & 10 \\
\hline
\end{tabular}

\subsection{Data analysis}

The analysis of the demographic information (i.e. frequency, mean, and standard deviation) and the repeated measures MANCOVA analysis of variance were run using SPSS 16 (SPSS Inc., Chicago, Illinois, USA). P-value less than 0.05 was considered statistically significant 


\subsection{Ethical Considerations}

Prior to the research, a briefing session was held for the patients. In this session, moral considerations and the research were explained to the patients. Afterwards, the written informed consent of all the participants was obtained, and the participants were assured that the research results and their identities would be kept confidential and their medical information would be solely disclosed to the medical team. This research was assessed by the Ethics Committee of Kashan University of Medical Sciences beforehand (Ref: IR.KAUMS.MEDNT.REC.1396.6). This research was registered at the Iranian Registry of Clinical Trials with the IRCT ID: IRCT2017092532057N2.

\section{Results}

Of the 75 participants in this study, one of the members of the experimental group was not willing to continue participation in this research due to unexplained absence. Finally, the data on 74 of the participants (24 in the experimental group, 25 in the active control group, and 25 in the treatment-as-usual group) were analyzed. The demographic properties of the participants are listed in Table 2. The average age of the participants in the experimental group, the active control group, and the TAU group was 37.6 (7.05), 38.32, and 36.4 (6.9) years, respectively. There was no significant difference among the groups in terms of age $(p<0.05)$, and there was also no significant difference among the groups in terms of the diagnosis type, gender, marital status, and academic status $(\mathrm{p}<0.05$, Table 2$)$. The results of the body image flexibility questionnaire and the body awareness questionnaire for all of the three groups were assessed by repeated measures (using ANOVA). As seen in Table 3, prior to the intervention, there was no significant difference among the three groups regarding body image flexibility and body awareness. However, in the posttest and follow-up, a significant improvement in the scores of the body image flexibility questionnaire and body awareness questionnaire was displayed by the experimental group as compared to the active control and the TAU groups $(\mathrm{p}<0.05)$. Also, Table 4 shows the Scheffe test of variables difference among stages measurements.

Table 2. Assessment of the demographic information of the three groups

\begin{tabular}{|c|c|c|c|c|c|}
\hline \multicolumn{2}{|c|}{ Demographic characteristic } & $\begin{array}{l}\text { Intervention } \\
\text { group }\end{array}$ & $\begin{array}{l}\text { Active control } \\
\text { group }\end{array}$ & $\begin{array}{l}\text { TAU } \\
\text { group }\end{array}$ & $\begin{array}{l}\mathrm{p}- \\
\text { value }\end{array}$ \\
\hline \multicolumn{2}{|l|}{ Age (year); Mean \pm SD } & $37.6(7.05)$ & $38.32(7.47)$ & $36.4(6.9)$ & $0.75^{*}$ \\
\hline \multirow[t]{2}{*}{ Gender; n (\%) } & Male & $10(41)$ & $8(32)$ & $11(44)$ & \multirow[t]{2}{*}{$0.48 * *$} \\
\hline & Female & $14(59)$ & $17(68)$ & $14(66)$ & \\
\hline \multirow{3}{*}{$\begin{array}{l}\text { Academic status; } n \\
(\%)\end{array}$} & Guidance school & $11(45.5)$ & $12(48)$ & $10(40)$ & \multirow[t]{3}{*}{$0.62 * *$} \\
\hline & High school & $9(37)$ & $8(32)$ & $10(40)$ & \\
\hline & University & $4(17.5)$ & $5(20)$ & $5(20)$ & \\
\hline \multirow[t]{3}{*}{ Marital status; n (\%) } & Single & $3(12.5)$ & $7(28)$ & $5(20)$ & \multirow[t]{3}{*}{$0.32 * *$} \\
\hline & Married & $17(70)$ & $16(64)$ & $18(72)$ & \\
\hline & Other & $4(17.5)$ & $2(8)$ & $2(8)$ & \\
\hline \multirow[t]{5}{*}{ Diagnosis; n (\%) } & Illness anxiety & $7(29)$ & $9(36)$ & $8(32)$ & \multirow[t]{5}{*}{$0.70^{* *}$} \\
\hline & Somatic symptom disorder & $10(42)$ & $9(36)$ & $8(32)$ & \\
\hline & Conversion disorder & $2(8)$ & $2(8)$ & $3(12)$ & \\
\hline & Psychological factors & $5(21)$ & $5(20)$ & $6(24)$ & \\
\hline & $\begin{array}{l}\text { Influencing physical } \\
\text { diseases }\end{array}$ & $24(100)$ & $25(100)$ & $25(100)$ & \\
\hline
\end{tabular}

* Independent-samples t-test, ** Pearson's Chi-square test, SD: Standard deviation

Table 3. Repeated measure of variables

\begin{tabular}{|l|l|l|l|l|l|l|l|l|l|l|}
\hline Variables & Pre-test & & \multicolumn{3}{|l|}{ Post-test } & & Follow-up & $\begin{array}{l}\text { p- } \\
\text { value* }\end{array}$ \\
\cline { 2 - 10 } & $\begin{array}{l}\text { Intervention } \\
\text { group }\end{array}$ & $\begin{array}{l}\text { Active } \\
\text { control } \\
\text { group }\end{array}$ & $\begin{array}{l}\text { TAU } \\
\text { group }\end{array}$ & $\begin{array}{l}\text { Intervention } \\
\text { group }\end{array}$ & $\begin{array}{l}\text { Active } \\
\text { control } \\
\text { group }\end{array}$ & $\begin{array}{l}\text { TAU } \\
\text { group }\end{array}$ & $\begin{array}{l}\text { Intervention } \\
\text { group }\end{array}$ & $\begin{array}{l}\text { Control } \\
\text { group }\end{array}$ & $\begin{array}{l}\text { TAU } \\
\text { group }\end{array}$ & \\
\hline $\begin{array}{l}\text { Body image; } \\
\text { Mean (SD) }\end{array}$ & $\begin{array}{l}63.3 \\
(10.08)\end{array}$ & $\begin{array}{l}62 \\
(10.44)\end{array}$ & $\begin{array}{l}61 \\
(11.5)\end{array}$ & $44.3(12.3)$ & $60(11.5)$ & $\begin{array}{l}60.1 \\
(13.4)\end{array}$ & $49.5(13.6)$ & $\begin{array}{l}62.2 \\
(11.8)\end{array}$ & $\begin{array}{l}55.4 \\
(16)\end{array}$ & 0.02 \\
\hline $\begin{array}{l}\text { Body awareness; } \\
\text { Mean (SD) }\end{array}$ & $59.7(13.8)$ & $\begin{array}{l}58.3 \\
(14.3)\end{array}$ & $\begin{array}{l}57.5 \\
(14.3)\end{array}$ & $72(12.9)$ & $\begin{array}{l}62.2 \\
(14.8)\end{array}$ & $\begin{array}{l}62.7 \\
(11.5)\end{array}$ & $70.6(13.9)$ & $\begin{array}{l}60.6 \\
(11.6)\end{array}$ & $\begin{array}{l}59.6 \\
(13.8)\end{array}$ & 0.02 \\
\hline
\end{tabular}

* Analysis of variance (ANOVA); TAU: treatment as usual 
Table 4. Scheffe test of variables difference among stages measurements

\begin{tabular}{|c|c|c|c|c|}
\hline \multicolumn{3}{|l|}{ Variables/ Group } & Mean difference & p-value* \\
\hline \multirow[t]{3}{*}{ Body image } & \multirow[t]{2}{*}{ Experimental group } & Active control group & -9.03 & 0.01 \\
\hline & & TAU & -6.51 & 0.04 \\
\hline & Active control group & TAU & 2.52 & 0.403 \\
\hline \multirow[t]{3}{*}{ Body awareness flexibility } & \multirow[t]{2}{*}{ Experimental group } & Active control group & 7.07 & 0.015 \\
\hline & & TAU & 7.5 & 0.035 \\
\hline & Active control group & TAU & 0.42 & 0.98 \\
\hline
\end{tabular}

* Scheffe test; TAU: treatment as usual

\section{Discussion}

This trial indicated that the ACT is significantly effective in improving body image flexibility and body awareness in patients with psychosomatic disorders. Since, usually medically ill patients express more negative feelings toward their bodies than healthy persons, patients tend to focus on dissatisfaction of the body part or the function affected by the illness and finally cause experiential avoidance. In this regard, studies that have worked on body consciousness and awareness have found that by decreasing the experiential avoidance, psychological flexibility will improve $(35,42)$. For instance, the effect of mindfulness exercises on body awareness in women with sexual dysfunction were reflective of the considerable contribution of mindfulness exercises to the improvement in the symptoms of sexual dysfunction and the body-image problem (31). On the other hand, the combination of mindfulness techniques and the acceptance and cognitive techniques was considerably successful in improving body awareness and the symptoms of comorbidity of depression and chronic pain in the clinical population (43). In fact, it is possible to raise body awareness in these patients by teaching them self-regulation, introspection strategies, and emotional regulation. Accordingly, increased body awareness leads to an improvement in the symptoms of chronic pain and depression (43). The results of various studies have unraveled the direct relationship of the dimensions of mindfulness with the different aspects of body awareness. In fact, the "awareness" component of mindfulness is strongly and directly associated with the "awareness" component of body awareness. On the other hand, "awareness" is an integral part of the ACT; hence, this therapy is expected to positively influence body awareness $(37,44)$. The results of the studies on the effectiveness of ACT for body image flexibility are in line with the findings from the present research. For instance, Abasi et al. (34), investigated the effectiveness of ACT in improving body image in girls with binge-eating disorder. Their results showed that this therapeutic method treated the symptoms of this disorder and improved body image in patients more effectively than the control group.

In the present study, it can be claimed that the increase in body awareness is due to consciousness and will expand the concept of mindfulness in the ACT by paying particular attention to physical sensations, introspective sense, experiential emotions, movements and gestures that show up in sessions between client and therapist. Also, there is relationship between body awareness and body image flexibility which conveys that the greater the body awareness, the greater the body image flexibility (41). Also, the research by Linde et al. (30), indicated that acceptance-based exposure therapy can successfully correct dysfunctional body images in women with body dysmorphic disorder. Furthermore, the results of the studies on the effectiveness of ACT for body image flexibility are in line with the findings from the present research. The results of the present study also support the Selby's study (41) finding that ACT is effective in increasing body image flexibility and satisfaction. The finding of this study was that ACT was better than an active control therapy at post treatment and follow-up. The results are both consistent with Sandoz (39), who demonstrated that ACT led to improved body image flexibility.

This study determined that ACT improves body image flexibil ity (through psychological flexibility). ACT causes biased attention separate from the body-related stimuli in patients with psychosomatic problems (34). In fact, the patient with psychosomatic problems that have this biased attitude becomes fused with these biases, which also plays a major role in the development of psychosomatic problems. In this therapy, body awareness and body image flexibility are increased by teaching self-regulation, introspection strategies, and emotional regulation $(30,41)$.

\section{Limitations}

The current study has some limitations. Firstly, the follow-up phase was not long. Secondly, since Kashan City has a small population, it was not possible to compare other acceptance- and mindfulness-based therapies (such as dialectical behavior therapy) with ACT. Therefore, it is recommended to examine the results of the ACT intervention in the long run and compare other treatments. Moreover, in order to shorten the treatment period, it is 
http://www.ephysician.ir

possible to compare the dimensions of mindfulness with the treatment outcomes to find the strongest dimensions of mindfulness that contribute to the recovery of these patients

\section{Conclusions}

This study addresses the role of mindfulness based therapy ACT in psychological flexibility in psychosomatic patients. Clinicians learn to assist the clients in a method of mindful self-study that helps them to become aware of how their body organizes experiences and vice versa. Also, this study highlights that ACT interventions for body image flexibility shows promise, and investment in future research using larger and higher quality randomized controlled trials is required to confirm the effectiveness of ACT in body related variables.

\section{Acknowledgments:}

The authors hereby express their gratitude to the honorable personnel of Shahid Beheshti Hospital of Kashan, who provided assistance in the course of this research. The authors are also truly thankful to the esteemed Research and Technology Department of Kashan University of Medical Sciences for funding this research.

\section{Conflict of Interest:}

There is no conflict of interest to be declared.

\section{Authors' contributions:}

All authors contributed to this project and article equally. All authors read and approved the final manuscript.

\section{References:}

1) Association AP. Diagnostic and statistical manual of mental disorders (DSM-5®): American Psychiatric Pub; 2013.

2) Cosci F, Fava GA. The clinical inadequacy of the DSM-5 classification of somatic symptom and related disorders: an alternative trans-diagnostic model. CNS Spectr. 2016;21(4):310-7. doi: $10.1017 / \mathrm{S} 1092852915000760$.

3) Fava GA, Cosci F, Sonino N. Current psychosomatic practice. Psychother Psychosom. 2017;86(1):13-30. PMID: 27884006.

4) Kaplan BJ. Kaplan and Sadock's Synopsis of Psychiatry. Behavioral Sciences/Clinical Psychiatry. Tijdschrift voor Psychiatrie. 2016;58(1):78-9.

5) Cohane GH, Pope HG. Body image in boys: A review of the literature. Int J Eat Disord. 2001;29(4):373-9. PMID: 11285574.

6) Kockerling, E., J. Breckenkamp, and B. Hesse, [Relationship Between The Use of Psychosomatic Rehabilitation and Regional Capacities for Medical and Psychotherapeutic Treatment of Mental Disorders in Westphalia]. Gesundheitswesen, 2018. PMID: 29758574, doi: 10.1055/a-0600-2662.

7) Desai KM, Kale AD, Shah PU, Rana S. Psychosomatic Disorders: A Clinical Perspective and Proposed Classification System. Arch Iran Med. 2018;21(1):44. PMID: 29664670

8) Deter H-C, Kruse J, Zipfel S. History, aims and present structure of psychosomatic medicine in Germany. Biopsychosoc Med. 2018;12(1):1. PMID: 29434655, doi: 10.1186/s13030-017-0120-x

9) Ferrari S, Poloni N, Diefenbacher A, Barbosa A, Cosci F. From hysteria to somatic symptom disorders: searching for a common psychopathological ground. Official Journal of the Italian Society of Psychopathology Organo Ufficiale della Società Italiana di Psicopatologia. 1989;46:372-9.

10) Watanabe J, Watanabe M, Yamaoka K, Adachi M, Nemoto A, Tango T. Effect of School-Based HomeCollaborative Lifestyle Education on Reducing Subjective Psychosomatic Symptoms in Adolescents: A Cluster Randomised Controlled Trial. PloS one. 2016;11(10):e0165285. PMID: 27780251, doi: 10.1371/journal.pone.0165285

11) Ebert D, Hannig W, Tarnowski T, Sieland B, Götzky B, Berking M. Web-based rehabilitation aftercare following inpatient psychosomatic treatment. Rehabilitation (Stuttg). 2013;52(3):164-72. PMID: 23761205, DOI:10.1055/s-0033-1345191

12) Rief W, Mewes R, Martin A, Glaesmer H, Brähler E. Evaluating new proposals for the psychiatric classification of patients with multiple somatic symptoms. Psychosom Med. 2011;73(9):760-8. PMID: 22048838, DOI: 10.1097/PSY.0b013e318234eff6

13) Creed F, Barsky A. A systematic review of the epidemiology of somatisation disorder and hypochondriasis. J Psychosom Res. 2004;56(4):391-408. PMID: 15094023, DOI: 10.1016/S0022-3999(03)00622-6 
14) King IC. Body image in paediatric burns: a review. Burns Trauma. 2018;6(1):12. PMID: 29744373, DOI: 10.1186/s41038-018-0114-3

15) Yazdani N, Hosseini SV, Amini M, Sobhani Z, Sharif F, Khazraei H. Relationship between Body Image and Psychological Well-being in Patients with Morbid Obesity. Int J Community Based Nurs Midwifery. 2018;6(2):175. PMID: 29607346

16) Grossman SL, Campagna B, Brochu H, Odermatt M, Annunziato RA. Improving body image and sexual health behaviors among college women. J Am Coll Health. 2018(just-accepted):1-15. PMID: 29565752, DOI: $10.1080 / 07448481.2018 .1454927$

17) Schmidt U, Treasure J. Anorexia nervosa: Valued and visible. A cognitive-interpersonal maintenance model and its implications for research and practice. Br J Clin Psychol. 2006;45(3):343-66. PMID: 17147101

18) Grant A, Townend M, Mills J, Cockx A. Assessment and case formulation in cognitive behavioural therapy: Sage; 2008.

19) Wendell JW, Masuda A, Le JK. The role of body image flexibility in the relationship between disordered eating cognitions and disordered eating symptoms among non-clinical college students. Eat Behav.2012;13(3):240-5. PMID: 22664403, DOI: 10.1016/j.eatbeh.2012.03.006

20) Grogan S. Body image: Understanding body dissatisfaction in men, women and children: Taylor \& Francis; 2016.

21) Murakami M, Nakai Y. Current state and future prospects for psychosomatic medicine in Japan. Biopsychosoc Med. 2017;11(1):1. PMID: 28105067, DOI: 10.1186/s13030-017-0088-6

22) Harvie RM, Chisholm AW, Bisanz JE, Burton JP, Herbison P, Schultz K, et al. Long-term irritable bowel syndrome symptom control with reintroduction of selected FODMAPs. World J Gastroenterol. 2017;23(25):4632. PMID: 28740352, DOI: 10.3748/wjg.v23.i25.4632

23) Seferiadis A, Ohlin P, Billhult A, Gunnarsson R. Basic body awareness therapy or exercise therapy for the treatment of chronic whiplash associated disorders: a randomized comparative clinical trial. Disabil Rehabil. 2016;38(5):442-51. PMID: 25955823, DOI: 10.3109/09638288.2015.1044036

24) Garbarini F, Pia L. Bimanual coupling paradigm as an effective tool to investigate productive behaviors in motor and body awareness impairments. Front Hum Neurosci. 2013;7:737. PMID: 24204339, DOI: 10.3389/fnhum.2013.00737

25) Hofmann SG, Asnaani A, Vonk IJ, Sawyer AT, Fang A. The efficacy of cognitive behavioral therapy: A review of meta-analyses. Cognit Ther Res. 2012;36(5):427-40. PMID: 23459093, DOI: 10.1007/s10608012-9476-1

26) Matsuoka H, Chiba I, Sakano Y, Toyofuku A, Abiko Y. Cognitive behavioral therapy for psychosomatic problems in dental settings. Biopsychosoc Med. 2017;11(1):18. PMID: 28630646, DOI: 10.1186/s13030017-0102-z

27) Cayoun BA. Mindfulness-integrated CBT for well-being and personal growth: Four steps to enhance inner calm, self-confidence and relationships: John Wiley \& Sons; 2014.

28) Yazdanimehr R, Omidi A, Sadat Z, Akbari H. The effect of mindfulness-integrated cognitive behavior therapy on depression and anxiety among pregnant women: a randomized clinical trial. J Caring Sci. 2016;5(3):195. PMID: 27752485, DOI: 10.15171/jcs.2016.021

29) Cayoun BA. Mindfulness-integrated CBT: Principles and practice: John Wiley \& Sons; 2011.

30) Linde J, Rück C, Bjureberg J, Ivanov VZ, Djurfeldt DR, Ramnerö J. Acceptance-based exposure therapy for body dysmorphic disorder: A pilot study. Behav Ther. 2015;46(4):423-31. PMID: 26163707, DOI: 10.1016/j.beth.2015.05.002

31) Silverstein RG, Brown A-CH, Roth HD, Britton WB. Effects of mindfulness training on body awareness to sexual stimuli: implications for female sexual dysfunction. Psychosom Med. 2011;73(9):817. PMID: 22048839, DOI: 10.1097/PSY.0b013e318234e628

32) Davoudi M, Omidi A, Sehat M, Sepehrmanesh Z. The Effects of Acceptance and Commitment Therapy on Man Smokers' Comorbid Depression and Anxiety Symptoms and Smoking Cessation: A Randomized Controlled Trial. Addict Health. 2017;9(3):129. PMID: 29657693

33) Blackledge JT, Ciarrochi J, Deane FP. Acceptance and commitment therapy: contemporary theory research and practice: Australian Academic Press; 2009.

34) Abbasi M, Porzoor P, Moazedi K, Aslani T. The Effectiveness of Acceptance and Commitment Therapy on Improving Body Image of Female Students with Bulimia Nervosa. J Ardabil Univ Med Sci. 2015; 15 (1) $: 15-24$ 
35) Callaghan GM, Duenas JA, Nadeau SE, Darrow SM, Van der Merwe J, Misko J. An empirical model of body image disturbance using behavioral principles found in Functional Analytic Psychotherapy and Acceptance and Commitment Therapy. Int J Behav Consult Ther. 2012;7(2-3):16. PMID: 23997716

36) Stewart TM. Light on body image treatment: Acceptance through mindfulness. Behav Modif. 2004;28(6):783-811. PMID: 15383686, DOI: 10.1177/0145445503259862

37) Vowles KE, Fink BC, Cohen LL. Acceptance and Commitment Therapy for chronic pain: A diary study of treatment process in relation to reliable change in disability. J Contextual Behav Sci. 2014;3(2):74-80. PMID: 27818931, DOI: 10.1016/j.jcbs.2014.04.003

38) Izaadi A, Karimi J, Rahmani M. Psychometric Analysis of Persian Version of Body Image flexibility Questionnaire (BI-AAQ) among University students. Hayat. 2013; 19 (3) :56-69.

39) Sandoz EK, Wilson KG, Merwin RM, Kellum KK. Assessment of body image flexibility: the body imageacceptance and action questionnaire. J Contextual Behav Sci. 2013;2(1-2):39-48.

40) Taherifar Z, Ferdowsi S, Mootabi F, Mazaheri MA, Fata L. The mediating role of emotion dysregulation strategies on the relationship between negative emotion intensity and safety motivation with generalized anxiety symptoms. Contemporary psychol. 2016;10(2):51-66.

41) Selby CL. Acceptance and Commitment Therapy for Body Image Dissatisfaction: A Practitioner's Guide to Using Mindfulness, Acceptance and Values-Based Behavior Change Strategies: by Adria N. Pearson, Michelle Heffner, and Victoria M. Follette. Oakland, CA: New Harbinger Publications, 2010, Taylor \& Francis; 2011.

42) Fogelkvist M, Parling T, Kjellin L, Gustafsson SA. A qualitative analysis of participants' reflections on body image during participation in a randomized controlled trial of acceptance and commitment therapy. J Eat Disord. 2016;4(1):29. PMID: 27999670, DOI: 10.1186/s40337-016-0120-4

43) de Jong M, Lazar SW, Hug K, Mehling WE, Hölzel BK, Sack AT, et al. Effects of mindfulness-based cognitive therapy on body awareness in patients with chronic pain and comorbid depression. Front Psychol. 2016;7:967. PMID: 27445929, DOI: 10.3389/fpsyg.2016.00967

44) del CQ-BL, Gonzalez-Ramirez MT, Cebolla A, Soler J, Garcia-Campayo J. Body awareness and mindfulness: validation of the Spanish version of the Scale of Body Connection. Actas Esp Psiquiatr. 2014;42(2):57-67. PMID: 24715363 